\title{
Preoperative prism adaptation test in normosensoric strabismus
}

\author{
Annette Schildwächter-von Langenthal, Guntram Kommerell, Ulrike Klein, and Huibert Jan Simonsz \\ Abteilung für Neuroophthalmologie und Schielbehandlung, Universitäts-Augenklinik, Killianstrasse 5, D-7800 Freiburg, \\ Federal Republic of Germany
}

\begin{abstract}
In 19 patients with normosensoric esotropia, the squint angles measured with the alternate cover test were compared with those after prolonged prismatic correction of the squint angle and with those after prolonged occlusion of one eye. All patients showed an increase of the squint angle after prism adaptation. The angle was generally smaller after diagnostic occlusion of one eye than after prism adaptation. We assume that the increase in the squint angle after prism adaptation is caused by an anomalous sensorial relationship between the two eyes that was not detected with the usual psychophysical tests. Surgery tailored to the squint angle after prism adaptation seems advisable in patients with normosensoric esotropia.
\end{abstract}

\section{Introduction}

The preoperative prism adaptation test [6] simulates the postoperative change of the location of the retinal image. Using the prism adaptation test, postoperative sensomotoric reactions can be predicted, in particular a recurrence of the original convergent angle. It is known that in esotropia with anomalous retinal correspondence, the squint angle often increases during prism adaptation. This anomalous fusional movement reestablishes the retinal image location on the basis of anomalous retinal correspondence.

After prism correction of an esotropic angle in patients with normal retinal correspondence, one would expect binocular single vision and not an increase in the deviation. However, we have observed cases where the angle of squint increased during prism adaptation, although the retinal correspondence was normal. In the present study we examined this phenomenon systematically.

\section{Patients and methods}

\section{Patient selection}

All normosensoric esotropes who had surgery between 1985 and 1987 were included in this study if they fulfilled the following four criteria:

1. Onset of squint after the age of 2 years or intermittent strabismus

2. Central fixation in both eyes

Offprint requests to: $\mathrm{G}$. Kommerell
3. Good visual acuity in both eyes ( 0.8 or better)

4. Normal retinal correspondence and fusion

In patients with constant strabismus, the subjective angle was measured at the synoptophore (Clement-Clarke) with fusion slides; large pictures were used, i.e., the "cleaning cats" (horizontal extension $6^{\circ}$; vertical extension $8^{\circ}$ ). The angle was adjusted by the patient so that he or she had single vision. The patient was then asked to fixate a detail seen binocularly. If there was no movement when the light of the right or left tube was switched off, fusion with normal retinal correspondence was diagnosed. In patients with intermittent strabismus, orthotropia on the unilateral cover test was taken as an indication of fusion with normal retinal correspondence. Other methods for testing retinal correspondence were also used - for instance, dissimilar slides at the synoptophore such as "lion and cage", afterimages (Hering) and, in the case of intermittent strabismus, striated glasses (Bagolini). The results usually coincided, although suppression was more often reported when nonfusional pictures were presented to both foveae.

Nineteen patients fulfilled these requirements. One was included who had an anisometropic amblyopia of 0.4 . The postoperative period of observation was at least 4 months. One patient was operated upon twice. All patients were tested while wearing full-refractive correctional spectacles or contact lenses.

\section{Procedure}

First, the "basic deviation" was determined by means of the alternating cover test. This angle was fully corrected or slightly overcorrected with prisms (Fresnel press-on prisms or, rarely, glass prisms) in front of the deviating eye. After 15 to $90 \mathrm{~min}$, the unilateral cover test was performed to check whether the angle of squint had increased or not. The alternating prism cover test was repeated and the prisms were changed accordingly. This procedure was continued until no further increase occurred; usually, this was the case after $6 \mathrm{~h}$. Following the prism adaptation test, the deviating eye was occluded for approximately $6 \mathrm{~h}$. The angle of squint was then measured again with the alternating cover test. Surgery was performed the following day. In most cases, the amount of surgery was based on the angle found after prism adaptation. Approximately $1 \mathrm{~mm}$ (bilateral recession of the medial rectus, or unilateral recession of the medial rectus and resection of the lateral rectus) was used for every 3 prism diopters. Postoperatively, the 
angle of squint was measured 2 days and 4 months after surgery with the unilateral and alternating cover test. Stereopsis was tested with one or more of the following tests: TNO, Titmus, and/or Lang.

\section{Results}

Figures 1 and 2 show a compilation of the angles measured with the alternating cover test under different conditions. An increase in the angle of squint occurred in all cases during prism adaptation. After monocular occlusion, the angle that had increased decreased again in all but three patients. These three patients did not differ significantly in any other respect from the others. In most cases, the angle after monocular occlusion was only slightly larger than the basic angle. Two days after surgery, five patients were exotropic at distance fixation. After 4 months, the overcorrections had disappeared. One patient had a residual esotropia of 4 prism diopters at distance fixation. Two patients had an esotropia only at near fixation. After surgery, three patients had a stereopsis disparity threshold of 60", four patients of $120^{\prime \prime}$, two patients of $240^{\prime \prime}$, one patient of $480^{\prime \prime}$, and two patients of $1980^{\prime \prime}$. In seven patients no stereopsis could be demonstrated - despite orthotropia. Two cases are described in detail.

\section{Case 16 (Figs. 1 and 2)}

This child was 5 years old when the mother observed a convergent squint of the right eye. On admission for surgery 9 months later, the esodeviation was manifest at all distances: $16^{\Delta}$ base out at distance and $18^{\Delta}$ base out at near fixation. At the synoptophore, normal retinal correspondence and stereopsis were demonstrated. Fusion could be maintained over a range of $16^{\circ}$. During the prism adaptation test, the angle increased to $30^{\Delta}$ and $35^{\Delta}$ base out. After monocular occlusion, the angle decreased to $25^{\Delta}$ and $18^{\Delta}$ base out. Surgery was performed on the right eye: recession of the medial rectus of $5 \mathrm{~mm}$ and resection of the lateral rectus of $5 \mathrm{~mm}$. Immediately after surgery, an esophoria of $2^{\Delta}$ and $4^{\Delta}$, and 4 months after surgery, an esophoria of $8^{\Delta}$ and $4^{\Delta}$ base out was found. Stereoacuity was $60^{\prime \prime}$ with the TNO test.

\section{Case 4 (Figs. 1 and 2)}

This patient's mother had observed a squint since the age of 3 years. On admission for surgery 9 months later, the child had an intermittent esotropia of $30^{\Delta}$ at distance and a constant esotropia of $30^{\Delta}$ at near. Normal retinal correspondence and stereopsis could be demonstrated at the synoptophore. During prism adaptation, the angle of squint increased to $50^{\Delta}$ base out at distance and $44^{\Delta}$ base out at near. After diagnostic occlusion, the angle decreased to $45^{\Delta}$ base out. The left eye was operated upon: medial rectus recession of $7 \mathrm{~mm}$ and lateral rectus resection of $7 \mathrm{~mm}$. Immediately after surgery there was a residual esotropia of $12^{\Delta}$ base out at distance and $14^{\Delta}$ base out at near. During the following 4 weeks, the deviation increased to $40^{\Delta}$ base out at all distances, and a second operation was planned. During the preoperative prism adaptation test, the angle again increased to $50^{\Delta}$ base out. This time, the right eye was operated on: recession of the medial rectus $7 \mathrm{~mm}$ and resection of the lateral rectus $7 \mathrm{~mm}$. Immediately after sur-

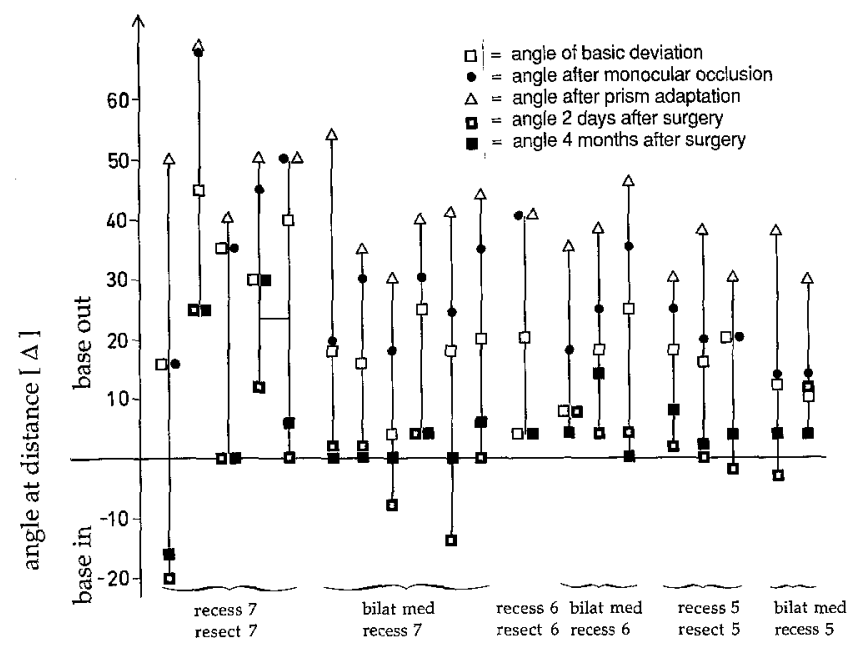

Fig. 1. Angles of squint for fixation at distance in 19 patients with normosensoric esotropia. All angles were measured using the alternate cover test and are expressed in prism diopters. Open squares, basic deviation; open triangles, after prolonged prismatic correction; filled circles, after prolonged occlusion of one eye; partly filled squares, 2 days after surgery; filled squares, 4 months after surgery. Patients are listed in groups according to the amount of muscle surgery $(\mathrm{mm})$, starting with case 1 on the left to case 19 on the right. Note that case 4 had been operated on twice and is hence represented twice. All patients showed an increase in the angle of squint after prism adaptation. The angle was generally smaller after diagnostic occlusion of one eye than after prism adaptation. We assume that the increase is caused by an anomalous sensorial relationship between the two eyes that was not detected with the usual psychophysical tests

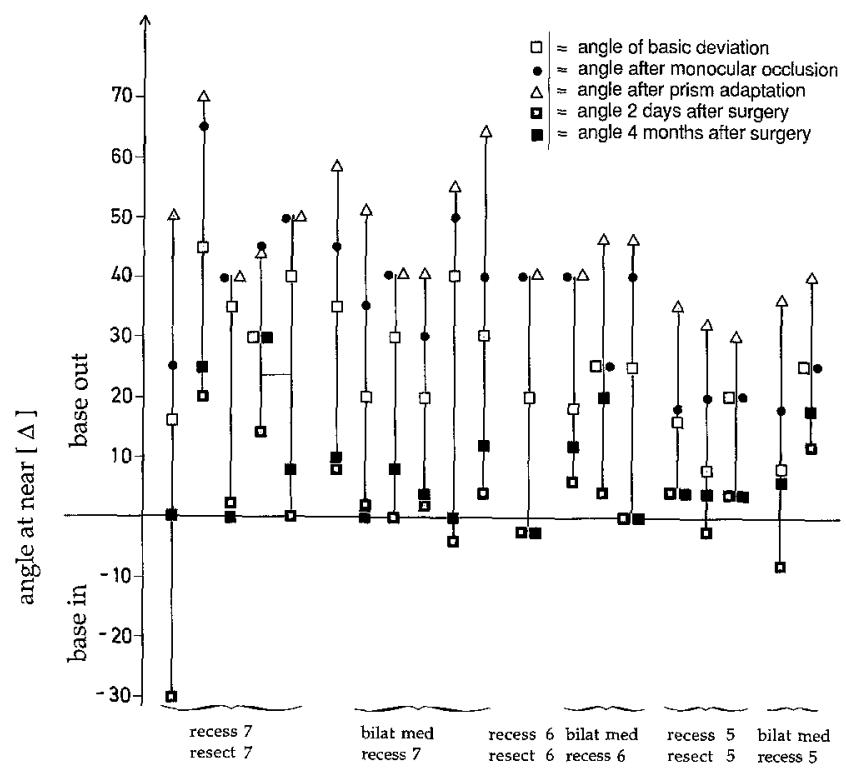

Fig. 2. Angles of squint for fixation at near

gery, the patient was orthophoric. Four months and 8 months later, the patient had an esophoria of $4^{\Delta}$ at distance and $6^{\Delta}$ base out at near. A stereoacuity of $60^{\prime \prime}$ was found with the TNO test.

These cases demonstrate that normal binocular single vision with good stereoacuity can be achieved despite a marked increase in the angle of squint during prism adaptation. 
To evaluate the effect of surgery, the dose-response ratio was determined, i.e., the difference between the preoperative and postoperative angles of squint per millimeter of surgery. In case 4 only the first operation was included. All dose-response ratios were calculated using the results 4 months postoperatively. The dose-response ratio based on the angle of squint after prism adaptation was $1.54 \pm 0.4 \mathrm{SD} \mathrm{deg} / \mathrm{mm}$ for fixation at distance and $1.56 \pm 0.39 \mathrm{SD} \mathrm{deg} / \mathrm{mm}$ for fixation at near. The dose-response ratio based on the basic deviation was $0.57 \pm 0.35 \mathrm{SD} \mathrm{deg} / \mathrm{mm}$ for fixation at distance and $0.68 \pm 0.42 \mathrm{SD} \mathrm{deg} / \mathrm{mm}$ for fixation at near. Based on the angle after monocular occlusion, the dose-response ratio was $0.99 \pm 0.35 \mathrm{SD} \mathrm{deg} / \mathrm{mm}$ for fixation at distance and $1.12 \pm 0.48 \mathrm{SD} \mathrm{deg} / \mathrm{mm}$ for fixation at near.

\section{Discussion}

In patients with anomalous retinal correspondence, an increase in the esodeviation during the prism adaptation test ("eating up prisms") has frequently been described [2-5]. This phenomenon has been termed anomalous fusional movement [4]. Apparently, patients try to regain the retinal image location to which they were accustomed. In esotropes with normal retinal correspondence (as determined with the methods mentioned above), prism correction should lead to binocular single vision, and an increase in the angle of squint is not to be expected.

However, we often observed an increase in the esodeviation during the prism-adaptation test in patients with normal retinal correspondence. This increase of the angle cannot be interpreted as a latent esodeviation because the angle was much smaller under diagnostic occlusion. Instead, we interpret the increase of the angle under prisms observed in our normosensoric patients as an anomalous fusional movement, in analogy to the phenomenon in patients with anomalous retinal correspondence.

Why were these anomalous connections not detected with the synoptophore? We suggest the following hypothesis: A suppression of the central retina of the squinting eye may have been present under casual seeing conditions, and anomalous retinal correspondence may have been present in the peripheral retina. When tested with the synoptophore, only the central $6^{\circ}-8^{\circ}$ area of the retina was stimulated. Under these conditions, the suppression of the central retina may have resolved so that normal retinal correspondence with fusion was demonstrated. During the prismadaptation test, the entire retina was stimulated, suppression of the central retina occurred, and fusional movements based on anomalous correspondence of the peripheral retina were elicited. This interpretation is supported by findings of Aulhorn [1] and of Sireteanu and Fronius [7] who demonstrated in strabismic patients the simultaneous occurrence of normal retinal correspondence in the center, to- gether with anomalous correspondence in the periphery of the visual field. As an alternative interpretation of the increase of the angle under prisms, we considered a convergence spasm that might have been triggered by the prisms. However, pseudomyopia and miosis were not observed in our patients.

The dose-response ratio for surgery, based on the angle of squint after prism adaptation and on the angle 4 months postoperatively, was $1.54 \pm 0.4 \mathrm{SD} \mathrm{deg} / \mathrm{mm}$, which is within the normal range. The dose-response ratios for surgery based on the basic deviation and on the angle after monocular occlusion were noticeably smaller: $0.57 \pm 0.35 \mathrm{SD} \mathrm{deg} /$ $\mathrm{mm}$ and $0.99 \pm 0.35 \mathrm{SD} \mathrm{deg} / \mathrm{mm}$, respectively. Although the dose-response ratio for the angles after prism adaptation was considerably higher than the other dose-response ratios, the standard deviations of the three dose-response ratios were similar. Therefore, the relative standard deviation of the dose-response ratio based on the angle of squint after prism adaptation was smaller. Consequently, the results of surgery guided by the angle of squint after prism adaptation should be more predictable.

In our group of 19 patients, binocular single vision with orthotropia was obtained postoperatively in 16 cases, whereas the remaining 3 cases had at least binocular single vision with orthotropia at either near or distance fixation. Hence, the conclusion of Bagolini et al. [3] that normal binocular vision can never be attained when "anomalous movements" (during prism adaptation) are strongly developed must be qualified. If fusion with normal retinal correspondence is found at the synoptophore, surgery can lead to orthotropia.

\section{References}

1. Aulhorn E (1968) Erfahrungen mit der Phasendifferenzhaploskopie. Ber Dtsch Ophthalmol Ges 69:593-598

2. Aust W, Welge-Lüssen L (1969) Prä- und postoperative Schielwinkelschwankungen nach längerem präoperativem Schielwinkelausgleich. Klin Monatsbl Augenheilkd 155:494-503

3. Bagolini B, Zanasi MR, Bolzani R (1986) Surgical correction of convergent strabismus: its relationship to prism compensation. Doc Ophthalmol 62:309-324

4. Campos EC, Bagolini B (1978) Der senso-motorische Aspekt des anomalen Binokularsehens: Die anomalen Fusionsbewegungen. In: Kommerell $G$ (ed) Disorders of ocular motility. Bergmann, München, pp 335-339

5. Halldén U (1952) Fusional phenomena in anomalous correspondence. Acta Ophthalmol [Suppl] 37:1-93

6. Jampolsky A (1971) A simplified approach to strabismus diagnosis. In: Trans New Orleans Academy Ophthalmol. Mosby, St. Louis, pp 67-75

7. Sireteanu R, Fronius M (1986) Verzerrte Raumwahrnehmung bei Amblyopen. Z Prakt Augenheilkd 7:243-246

Received July 27, 1988 / Accepted November 2, 1988 